\title{
DESIGNING AND LAUNCHING A YEAR-LONG EXECUTIVE EDUCATION PROGRAMME AT LSE CONFUCIUS INSTITUTE FOR BUSINESS LONDON - CHINESE LANGUAGE AND CULTURE FOR BUSINESS (CLCB)
}

\author{
Catherine Hua Xiang
}

London School of Economics and Political Science Phone: +447917010122, E-Mail: h.xiang@1se.ac.uk;

\begin{abstract}
This paper focuses on designing and launching the first year-long executive education programme, namely Chinese Language and Culture for Business (CLCB) at LSE (London School of Economics) in London. The essential features of this program include the curriculum design, delivery mode and on-going student support. A blended learning (BL) approach is adopted in the Mandarin teaching, with course delivery and assessment taking place in face-to-face contact hours in class, combined with the use of online learning environment and mobile technology out of class. This combination is used to meet the needs of busy business professionals, to provide them with online and offline support, and thus to maximise their learning outcome. From the intercultural communication perspective, the programme provides intensive training and business master sessions addressing core values of Chinese culture and Chinese business communication styles. The invited guest speakers who hold senior positions in different businesses areas share their live experiences with the students on the unique Chinese business concepts and practice such as 'hanxu' and 'heqishengcai'. Meanwhile, talks and events, from China Business Briefings to Open Business Forum, are organized to provide the students with global networking opportunities. Embedded in this program, a fortnight summer study trip to Tsinghua University enables students to fully immerse themselves in Chinese language and life. The paper addresses some practical considerations and challenges in designing the programme with the hope to shed light on and provide pedagogical implications for other programme leaders and course designers in the field of language teaching for specific purposes.
\end{abstract}

Key words: executive year-long programme, blended Chinese language learning, intercultural communication and business masterclass, global networking, business Chinese

\section{INTRODUCTION}

The state visit to China of Teresa May hinted a message that China, after nearly forty years of rapid economic development and social progress (since 1978), has become the world's second largest economy and played an increasingly important role in the global economy (The World Bank 2017). In the global business arena, the phenomenal growth of international business with China has created an escalating demand for the adequate awareness and knowledge of Chinese culture, which is of paramount importance in successful business communication. 
In the UK, China's strategic importance to British interests has generated government-funded initiatives to promote the teaching of Chinese as a modern foreign language in both schools and universities (Hughes, Lo \& Xu 2017). In September 2015 (HM Treasury), the former Chancellor of the Exchequer, George Osborne, confirmed the UK's commitment to Chinese and announced a £10-million fund to increase the quantity and quality of Chinese language teaching in schools. As might be expected, the increased demand for Mandarin Chinese is stimulating debates amongst researchers and teachers on how to meet learners' needs in the twenty-first century (Hughes, Lo \& Xu 2017).

The Confucius Institute for Business London (known as CIBL) was launched in 2006 with a mission to serve London business communities by providing top quality business Chinese language courses. Founded with the support of BP, Deloitte, HSBC, John Swire \& Sons (Swire Group), Standard Chartered, it is continuously supported by Confucius Institute Headquarters (Hanban), the Ministry of Education of The People's Republic of China and the Embassy of China in the UK. The Institute is run by the London School of Economics and Political Science (LSE), jointly with Tsinghua University in Beijing.

The Chinese Language and Culture for Business programme is a new education offer by CIBL which combines language skills, business skills, intercultural communication and study-abroad so that students can interact successfully with Chinese counterparts. This paper aims to address some practical considerations and challenges in designing this new executive programme with the view to provide pedagogical implications for other programme leaders and course designers in the field of language teaching for specific purposes.

\section{OVERVIEW OF THE PROGRAMME}

The Chinese Language and Culture for Business (CLCB) is a year-long part-time programme for business executives and professionals who have an interest in Chinese business communication and culture. This programme attempts to equip learners with three essential skills for doing successful business in China. 1) Being able to be engaged in informal conversations before getting down to business; 2) Having sufficient knowledge about Chinese culture and approaches to business; 3 ) Meeting like-minded people and expanding their global business world.

The most important consideration of the Chinese Language and Culture for Business executive education programme is that language learning for business takes form in different shapes and through different channels. The optimised learning outcome is achieved through a combination of carefully designed features, multiple learning contexts and activities to address the needs of highly mobile professionals. According to Craft and Mor (2012), learning design is "the creative and deliberate act of devising new practices, plans of activities, recourses and tools aimed at achieving particular educational aims in a given context." With such approach in mind, this programme focuses on learning experience instead of merely content.

The current programme contains three features and one optional two-week study trip to China. The three features are: 1) Blended Language Learning; 2) Intercultural Communication and Management; and 3) Global networking events. Each feature aims to address a particular aspect of the needs of learners. They also incorporate different theory and methodologies in the field of teaching language for specific purposes. The delivery modes include weekly language classes, full-day Saturday immersion, lectures on doing business 
with China and Chinese economy, socio-cultural events and networking opportunities, organized HSK examinations, mobile technology and online office hours etc.

Business Chinese language component is the core element of the CLCB programme. In total, six language levels (from complete beginners to proficiency) are offered and each level has its structured syllabus. This allows students to join the programme with no prior knowledge of Mandarin Chinese to those who are already fluent in daily conversation. Based on the market research and needs analysis, businessmen and professionals would like to speak Mandarin to build business relationship and rapport rather than conduct the whole business in Chinese. As a matter of fact, English remains to be the business language for contracts and any legal documents. Therefore, the business language class puts emphasis on listening and speaking skills on business context rather than reading and writing Chinese characters. The class size is capped at maximum twelve students. The face-to-face teaching takes place weekly for 40 weeks. Each weekly class lasts two hours. In addition, there are HSK/BCT qualification preparation classes on the first Saturday of each month for 10 consecutive months. Each preparation class lasts three hours. The total classroom language instruction counts 110 hours across ten months. Students will be then joining each other on other parts of the programme such as the Intercultural Communication training and events. The total contact hours of this programme are around 270 hours excluding the two weeks in China.

In the next section, details of each features and the interplay of different features will be described. For an overview of all specifications of the programme, please see Appendix A.

\section{PROGRAMME FEATURES}

\subsection{Blended approach to language learning}

The first feature of the CLCB programme is blended language learning (BL) approach and the application of such approach. BL is defined as the "thoughtful integration of face-to-face, classroom-based experiences and online learning" (Garrison \& Kanuka, 2004, p. 96). As an educational innovation, BL has a great impact on language education today (Diep, Zhu, Struyven, \& Blieck 2017; Wu, Tennyson, \& Hsia 2010). Using a mix of traditional education practices with a modern technology, BL combines the face-to-face instruction and asynchronous/synchronous online learning, which is strongly advocated by educational practitioners (Wu, Tennyson, \& Hsia 2010). As widely recognized, BL approach tends to maximise learning opportunities and build engaging learning experiences from an ecological perspective (Diep, Zhu, Struyven, \& Blieck 2017; Liu \& Chao 2018).

Typical blended language learning combines two delivery modes, namely face-to-face classroom teaching with online learning platforms or more recently mobile technology. The current programme in its application of BL combines multi delivery modes: face-to-face classroom teaching, Moodle, online drop-in sessions via Skype and APPs via mobile technology. The online drop-in sessions and mobile technology are designed specifically for this programme as it offers flexibility and accessibility that businessmen and women require. Students maintain the language contact with course teacher and peers even if they are on business trips regularly. Moreover, the understanding and knowledge of Chinese apps such as Alipay and Wechat is indispensable for business communication in China.

LSE uses Moodle as its online learning management system. Research has examined the use of learning management systems (LMS) like Blackboard and Moodle to engage learners 
(Blin \& Munro 2008; Hirschel 2012). Within the CLCB programme, a course site of each level is built through Moodle. Each Moodle course site contains four key components: 1 . The course content page; 2 . Discussion forum; 3. Individualised materials and 4. Online quizzes and e-feedback. Figure 1 shows a screen shot of the interface of the Moodle course site.

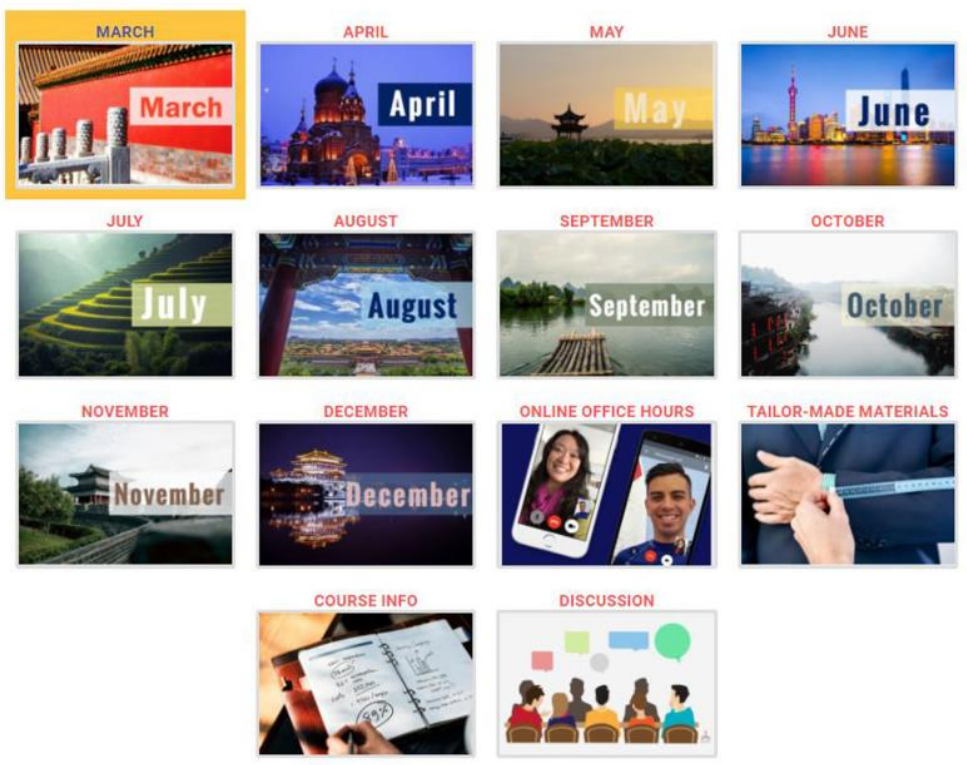

Fig. 1 Moodle course site screen shot

The weekly post consists of teaching video with weekly highlight from classroom learning and additional learning materials. It is designed for revision and self-motivated learning, and the discussion forum and e-feedback aim to encourage socially-mediated learning. Learner autonomy is expected to develop through self-motivated learning (independent learning) and socially- mediated learning (interdependent learning). With the CLCB Moodle, autonomous learning is expected to be achieved in a new ecological environment. One of the key elements of the weekly post is that it contains detailed instructions on how to best approach the learning materials and resources. Advices on self-study as well as specific learning strategies are also provided. The rationale is that without a framework of guiding principles, an educational intervention "will lack direction and may even, at its worst, become little more than a set of random interventions into the students' learning process" (Littlewood 1999, 80).

The discussion forum is used to create a context of transfer, where Mandarin Chinese learners could put what they have learned or acquired into use. The forum offers an informal and relaxed learning environment for learners to expand their vocabulary and receive corrections or feedback. Through the e-forum, they could exchange ideas about anything they are interested in. Additionally, they could raise questions for group discussion. When engaged in group-based forms of learning, the Mandarin Chinese learners are channeled to communicate in the target language. As a result, the discussion forum points to 'autonomous 
interdependence' (Littlewood 1999), which means that "autonomy develops most effectively in an interpersonal environment" (Littlewood 1999, 75). In order to ensure active involvement of all learners, the topics of discussion are initiated by teachers in the target language on a weekly basis regardless of whether there are any learners who start a discussion. The forum is then monitored, managed and co-constructed by both teachers and learners. All learners are encouraged to participate by teachers in the classroom setting. With time, more learners feel more comfortable to initiate discussion too.

Although the weekly courses have a structure with specified language input and learning outcomes, personalized learning pages are delivered through Moodle to reflect individual needs. Each student has a page containing texts, reading and vocabulary list that are relevant to their particular business industry or interest. Students are consulted on a regular basis in terms of the business situations or contexts where immediate language use or input can be helpful. It can vary from a welcome speech for an upcoming business trip to China or a recent piece of news of a particular sector that students works in. Students are identifying and driving the language input according to their immediate business environment. Moreover, using such ongoing dialogue with students, the most suitable format and type of learning activities could be designed to reflect individual learning styles. It becomes part of the teacher inquiry process (Clarke and Erickson 2003), where teachers examine their practice and its effects on students' learning in order to improve their practice.

On a monthly basis, the online team would offer interactive exercises on Moodle with e-feedback. These exercises aim to provide self-assessment and consolidation of key grammar points. Less face threatening, immediate and automated feedback may help the learners to break through limitations. During the process of e-revision, learners learn to take control of their learning activities, and gain awareness of strengthens and weaknesses. The learners can attempt a few practice sessions before the final timed quiz. During the practice sessions, the feedback will refer the learners to the page number of the textbook or provide additional explanation and examples. With the final quiz, the learners will be advised on their overall performance and suggestions for further improvement. On such an occasion, the e-feedback is deemed to be beneficial to the development of learner autonomy and achieve more effective learning outcomes.

As mentioned earlier, two additional elements of the blended learning feature are designed to enhance flexible learning opportunities and easier access. First, it is online drop-in sessions via Skype. Rather than traditional office hours where students are expected to come in person, online drop-in sessions are offered weekly. Planned slots with 30mins length each are offered to students a week in advance. Students book their preferred time slots via Doodle in the online forum. The online drop-in sessions primarily aim at conversational practice. Students can also use it to ask grammatical questions or consolidate the course content. Second, it is mobile technology with specific apps. Recent research has increasingly highlighted the importance of using smart phone and tablet in language learning (Rosell-Aguilar 2017; Yang \& Xie 2013). Three free apps and one paid app are included in the programme. The three free apps are Pleco, HSK app and Wechat. The paid app is Yiya Hanyu. The choices of the apps reflect specific skills: vocabulary, examination preparation, speaking and listening, pronunciation and business communication in China. Figures 2-4 show the interface of Pleco, HSK and Yiya Hanyu respectively. 


\begin{tabular}{|c|c|c|}
\hline \multicolumn{3}{|c|}{ HSK Level 1 - HSK 1 级 - } \\
\hline Enalish & Chingo & \\
\hline clothes & 衣服 & yī fu \\
\hline doctor & 医生 & yī shēng \\
\hline hospital & 医院 & yī yuàn \\
\hline chair & 椅子 & yǐ ziyǐ zi \\
\hline have, exist & 有 & yŏu \\
\hline month & 月 & yuè \\
\hline in, at & 在 & zài \\
\hline goodbye & 再见 & zài jiàn \\
\hline how & 怎么 & zěn me \\
\hline how about & 怎么样 & zěn me yàng \\
\hline this & 这 & zhè \\
\hline
\end{tabular}

Fig. 2 HSK APP

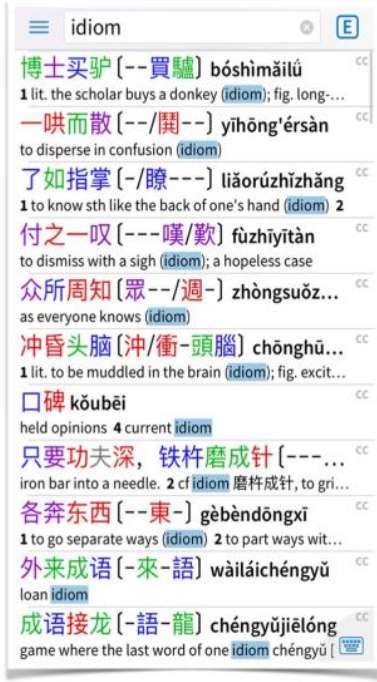

Fig. 3 Pleco APP

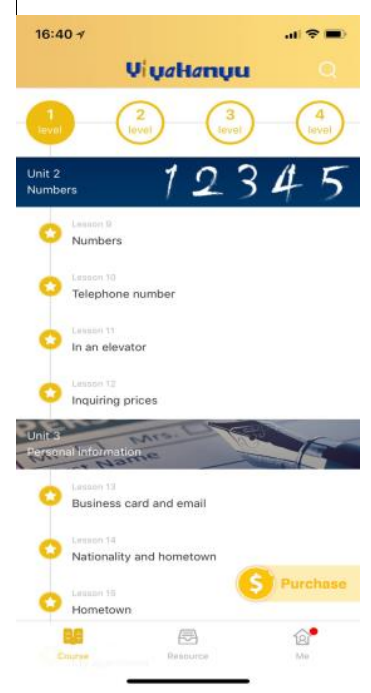

Fig. 4 YiyaHanyu APP

In summary, the CLCB programme operates BL at all four levels as suggested by Adams, Hanesiak, Owston, Lupshenyuk, \& Mills (2009): 1) the learning resources are available online as a support for the individual learning process; 2) the learning resources are well connected to what is happening in class, which assist both pre- and post-coursework; 3) the LMS plays a role in providing learning materials and facilities for collaborative discussions and peer support, and 4) face-to-face sessions and online learning activities are well coupled. It is all designed to engage students in learning with the help of various technological tools in additional to the classroom settings.

\subsection{Intercultural Communication and Management}

Intercultural communication and management trainings are another important feature of the CLCB programme. It aims to provide students deeper understanding of Chinese core values, communication styles and develop their intercultural competence. Intercultural competence is defined as the repertoire of knowledge, attitudes, and skills that are needed to interact effectively and appropriately in culturally diverse settings encountered at home or abroad (Bennett 1986; Deardorff 2006; Graf \& Harland 2005; Johnson et al. 2006). Effectiveness refers to an individual's ability to achieve the objectives established for an interaction, and appropriateness refers to an individual's ability to meet the basic contextual requirements of a given situation (Chen \& Starosta 1996). An interculturally competent person must have an understanding of different methods and styles of communication, an ability to interact with people from different cultural backgrounds and a desire to use their knowledge and abilities.

In the European context, intercultural competence has been developed on the model of linguistic competences, for which there is a continent-wide framework of reference. Capitalising on research by Byram (1997) and Risager (2007), a team of European researchers designed an evaluation tool - INCA (Intercultural Competence Assessment) 
-which conceptualizes intercultural competence along six dimensions: tolerance for ambiguity, behavioural flexibility, communicative awareness, knowledge discovery, respect for otherness, and empathy (Sinicrope, Norris, Watanabe 2007, 6-7). Evaluation of these dimensions assigns the assessed person the "basic", "intermediate" or "full" level.

In the CLCB programme, the trainings are conducted in English with essential linguistic strategies provided in Chinese. There are in total ten sessions with 3 hours each on Saturdays. Table 1 demonstrates the session outlines.

Table 1 Intercultural Communication Training Outline

\begin{tabular}{ll}
\hline Sessions & Session themes \\
\hline 1 & Language and Culture \\
2 & Intercultural Communication \\
3 & Pragmatics and Speech Acts \\
4 & Linguistic Politeness \\
5 & Core Chinese Values \\
6 & Chinese Communication Styles \\
7 & Individualism vs. Collectivism \\
8 & Chinese Concepts of 'Face'/Politeness \\
9 & Intercultural Communication and Negotiation \\
10 & Leadership and Multi-cultural teams \\
\hline
\end{tabular}

Important cultural concepts such as 'mianzi', 'guanxi', 'hanxu' and other linguistic features of the Chinese language are explored and analysed. Different case studies on miscommunication and cultural breakdowns in business contexts are examined and discussed. The intercultural communication and management sessions focus on enhancing students 'cultural awareness of China and its application in a range of business activities such as negotiation, leading an international team and managing cultural differences. From time to time, guest speakers with extensive knowledge and experience in doing business with China are invited to share their understanding. These are called 'Business Master classes'. There are plenty of opportunities for students to interact with the speakers and ask any questions related to partnerships with China at those sessions.

Instead of lecturing, the sessions take the form of seminar to encourage reflection and discussion. Case studies are essential part of the course to translate linguistic terms to real business contexts. For example, when introducing the concept of linguistic politeness, case studies on politeness in business meetings with Chinese delegates are examined with a range of tasks. The tasks can be to identify key politeness strategies used and its effectiveness and appropriateness to the given contexts. As might be expected, a range of meta-skills such as experiencing, exploring, analysing, evaluating, appreciating, respecting, accepting, self-reflecting, negotiating, and dialoguing are bound to be fostered and assessed as well. In this way, learners' intercultural knowledge (savoirs and savoir comprendre), intercultural skills (savoir apprendre and savoir s'engager), and intercultural awareness (savoir-être), coupled with their cultural identity could be developed (Houghton 2014).

\subsection{Events and networking}

From China Business Briefings to traditional festival celebrations, lectures and events are designed to optimise students' learning experience and provide them with networking 
opportunities. Networking in business is not a new concept. Pittway et al (2005) point out that the principal benefits of networking as identified in the literature include: risk sharing; obtaining access to new markets and technologies; speeding products to market; pooling complementary skills; safeguarding property rights when complete or contingent contracts are not possible; and acting as a key vehicle for obtaining access to external knowledge. Therefore, by actively incorporating this feature in the CLCB programme adds additional value to students.

China Business Briefing is a series of panel discussions held at LSE and it is open to the public. It explores the overarching question facing businesses today: What are the opportunities and challenges for businesses in China in view of current political, economical and social changes globally? Speakers come from diverse backgrounds and a range of companies, such as China-Britain Business Council, Industrial and Commercial Bank of China, Far East Facade, and many more. They are highly successful leaders and are generous in sharing what they have learnt from real-life experiences. Students on the CLCB programme are invited to VIP receptions after each China Business Briefing to have in depth conversation with speakers, peers and other native Chinese attendances. CIBL runs six China Business Briefings throughout the year and students on CLCB programmes are invited to all and entitled to three VIP receptions.

Other socio-cultural events include celebration of all traditional festivals of China such as Spring festival, Moon festivals. There are also film nights and organized visits to British museum, literature festivals and art galleries.

One of the key learning outcomes for students in such networking events is to experience what they have learned in the intercultural communication trainings in action. Take the concept 'guanxi' as an example, which is covered in the intercultural communication training. In Chinese, guanxi is a general term for social networking and is often translated as "relationship" or "connection." Guanxi refers to the establishment of a connection between two independent individuals to enable a bilateral flow of personal or social transactions. However, both parties must derive benefits from the transaction to ensure the continuation of such a relationship. According to Yeung and Tung (1996), guanxi differs from West concept of networking in the following six areas: the motives for engaging in social relations, reciprocation in social exchanges, time orientation, pattern of differentiation, nature of power, and sanction practice. The opportunities to network with both native Chinese business people in London and other delegates who shared the same interest in China in the programme facilitate practice and deeper understanding of how such key important concept could work in Chinese business and how it differs from a Western view.

\subsection{Summer trip to Tsinghua}

Sponsored by Confucius Institute Headquarters (Hanban), this optional study trip in China is a unique additional offer to all registered students on this executive programme. It allows students to build on their language foundation and improve their language skills in China.

In this trip, students will spend 2 weeks taking part in a series of tailor-made intensive business Chinese language programmes, including three hours of language learning per day plus field trips, cultural talks and networking events with Chinese counterparts. The course is designed by the Tsinghua University International Chinese Language \& Culture Centre (ICLCC) and provides a great opportunity for students to experience the real China. 
The link between Study Abroad (SA) and interculturality has been increasing recently and is now shared well beyond Europe (Beaven \& Borgheti 2016). SA brings into focus the students' intercultural relations and possibilities for intercultural development in relation to their stay abroad.

Regarding language skills and intercultural development resulting from study abroad programs, an extensive, multi-year study of student learning was carried out (Vande Berg, Connor-Linton, Paige 2009) and their findings showed gains in intercultural competence among the majority of the students. A study-abroad experience extends the classroom in the home country to the target culture, where students are involved in real-life intercultural communication. To explore learners' short-term SA on the development and maintenance of ICC, Shiri (2015) conducted a research of 352 students and found that students developed intercultural communication competence at the intermediate level, pertaining to completing daily activities. The study suggests that short-term SA can also have significant effects on intercultural communication competence development when carefully planned.

A short-term SA matches with the specific circumstances of students on the CLCB programme. The trip is made optional to avoid excluding those students who may not be able to take two weeks off from work. The weekly classes continue for those students who remain in London.

\section{ON-GOING STUDENT SUPPORT}

Students support starts before the programme begins with a well-planed consultation process. Students are all entitled to a free consultation with the programme director. This is an essential process to carry out the needs analysis of potential learners. The consultation has two main objectives: firstly, enable students to explain the reason for them to study Chinese language and culture for Business. Secondly, to enable the programme director to explain the key course features and identify the business context and linguistic needs of students. Different from language assessment, which does take place but separately, the consultation process records the motivation, objectives and particular business context where learners operate in so that all these will be taken into consideration when designing the course materials. This is key for building up the right individualised learning materials for each learner on Moodle.

Throughout the programme, regular revision and catch-up sessions are built into the curriculum. Many students on the programme need to travel for business or stay late for work. It is inevitable that they will miss some of the face-to-face sessions. Although Moodle offers the opportunity to keep up with the programme, regular revision sessions and catch-up sessions are designed to further reduce the negative impact of missing classes regularly. This is particularly crucial for complete beginner learners. Once they fall behind, it is harder for them to keep up with the pace of the courses.

On the social aspect, monthly Newsletters are sent to students to create a sense of community. The Newsletters contain personal stories of students and staff as well as their experience with China. It also shares relevant public lectures on China at LSE and all the other China-related events around London.

For students who attend the study trip to China, a pre-departure training is organized. The pre-departure training helps students with local knowledge of the Host University, Beijing and modern life in China. It addresses different styles in teaching and learning, the 
relationship between teachers and students and other cultural differences on education system between UK and China. Students can get help with all practical issues of the trip such as securing their visa, getting around the city, etc.

Finally, it is worth mentioning that regular programme evaluation is planned. Every two months, students are asked to provide feedback on teachers, language courses, intercultural communications and all the other aspects of the programme. Based on the evaluation, the programme management team can respond and provide most suited support to the students and most needed adjustment to the programme. Students' participation of each section of the programme is also monitored and recorded on a regular basis. Adopting the learning analytics practice (Long \& Siemens 2011), such evaluation and insights of the actual frequency of students' participation in different aspects of the programme can identify sections of the programme that most learners skim or skip without any negative effect and the sections most students enjoyed or struggled with, which may need to be strengthened or reworked. Learning analytics can improve decision making and resource allocation as well as provide interventions and transform pedagogical approaches. It is particularly useful for such new yet long-term programme.

\section{CHALlENGES}

As any new educational programme, there are many challenges to overcome. One of the key challenges for this programme is about how to ensure the overall coherence and the interconnectedness of all main features. This involves careful planning and on-going communication and liaison with teachers of different sections. For example, in an ideal scenario, the content of guest speakers for the business master class on Saturdays should be relevant to the topic of the Intercultural Communication training. However, subject to the availabilities of external speakers, this may not always be possible. Based on the feedback provided by the student of the current cohort so far, they do not consider it to be a major issue as they enjoy the variety of input on the day: HSK examine preparation, intercultural communication seminar which has a more academic focus and the business master class which presents views from practitioners.

The fact that the study trip is optional also presents challenges on the class management after they return. It is based on the assumption that the students who take part in the study trip will increase their linguistic competence and therefore causes gap between those who go to China and those who do not go after they return. Additional support may need to be provided to those who do not participate in the trip.

Student attendance and retention is another major issue for this kind of part-time yet long term executive course. Due to the specific profiles of students, full attendance is difficult to achieve. Many external factors such as change of roles or work pattern at work, relocation or other changes in personal life could all presents difficulties to complete the programme. The programme has built in a supporting system but it is too early to tell the effectiveness of such system.

Lastly, staffing capacity is a concern should the programme develop and grow. Currently, the lecturers of Intercultural Communication are from LSE but are not the same people as the Business Chinese teachers. Guest speakers of Business Masterclass and China Business Briefings are all external ones. This poses a challenge in scaling up the programme as more capacity of the teaching team is needed beyond just language teachers. 


\section{CONCLUSION}

This paper presents some pedagogical considerations and practical approaches in designing the new executive programme Chinese Language and Culture for Business. The paper specifically orients to integrating blended approach and technological innovation, an intercultural dimension as well as business skills to its language learning purpose. It aims provide an account of how these different features are developed, how resources are used, and how methodological approaches are adopted. It sheds some light on how further integration of language skills with culture and business skills could be achieved.

In sum, the combined effect of each course feature enables the CLCB programme to meet the needs of potential learners to the maximum extent. Learning Chinese for business is beyond learning the business vocabulary and grammar of the Chinese language. The need for flexibility and accessibility of learning as well as developing intercultural competence and understanding its application in real business contexts is the primary concern of the learners. A comprehensive and diverse curriculum design is essential to fulfil such needs. The blended approach with technological innovation is the means to facilitate the learning process. More research is needed to understand the best ratio for different features in such programme and the measurable effect of each and the combined effect of these features on students' linguistic and intercultural competence in their specific business contexts. Challenges remain on the on-going support to students and building staff capacity to ensure the sustainability of such programme.

\section{REFERENCES}

Adams, Jean M, R Hanesiak, G Morgan, R Owston, D Lupshenyuk, and L Mills. 2009. "Blended learning for soft skills development: Testing a Four-Level Framework for Integrating Work and Learning to Maximize Personal Practice and Job Performance, New York: Institute for Research on Learning Technologies."

Beaven, Ana, and Claudia Borghetti. 2016. Interculturality in study abroad. Language and Intercultural Communication, 16(3):313-317.

Bennett, Milton J. 1986. "A developmental approach to training for intercultural sensitivity." International journal of intercultural relations 10 (2):179-196.

Berg, Vande. 2009. "The Georgetown consortium project: Interventions for student learning abroad." Frontiers: The interdisciplinary journal of study abroad 18:1-75.

Blin, Françoise, and Morag Munro. 2008. "Why hasn't technology disrupted academics' teaching practices? Understanding resistance to change through the lens of activity theory." Computers \& Education 50 (2):475-490.

Byram, Michael. 1997. Teaching and assessing intercultural communicative competence: Multilingual Matters.

Chen, Guo-Ming, and William J Starosta. 1996. "Intercultural communication competence: A synthesis." Annals of the International Communication Association 19 (1):353-383.

Clarke, Anthony, and Gaalen Erickson (Eds). 2003. Teacher inquiry: living the research in everyday practice. London: Psychology.

Craft, Brock, and Yishay Mor. 2012. Learning design: mapping the lanscape. Research In Learning Techology 20: 85-94.

Deardorff, Darla K. 2006. "Identification and assessment of intercultural competence as a student outcome of internationalization." Journal of studies in international education 10 (3):241-266. 
Diep, Anh-Nguyet, Chang Zhu, Katrien Struyven, and Yves Blieck. 2017. "Who or what contributes to student satisfaction in different blended learning modalities?" British Journal of Educational Technology 48 (2):473-489.

Garrison, D Randy, and Heather Kanuka. 2004. "Blended learning: Uncovering its transformative potential in higher education." The internet and higher education 7 (2):95-105.

Graf, Andrea, and Lynn K Harland. 2005. "Expatriate selection: Evaluating the discriminant, convergent, and predictive validity of five measures of interpersonal and intercultural competence." Journal of Leadership \& Organizational Studies 11 (2):46-62.

Hirschel, Rob. 2012. "Moodle: Students' perspectives on forums, glossaries and quizzes." The Jaltcall Journal 8 (2):95-112.

Houghton, Stephanie Ann. 2014. "Exploring manifestations of curiosity in study abroad as part of intercultural communicative competence." System 42:368-382.

Hughes, Neil, Lan Lo, and Sujing Xu. 2017. "Blended Chinese language learning design: an integrative review and synthesis of the literature." The Language Learning Journal:1-19.

Johnson, James P, Tomasz Lenartowicz, and Salvador Apud. 2006. "Cross-cultural competence in international business: Toward a definition and a model." Journal of international business studies no. 37 (4):525-543.

Littlewood, William. 1999. "Defining and developing autonomy in East Asian contexts." Applied linguistics 20 (1):71-94.

Liu, Qian, and Chin-Chi Chao. 2018. "CALL from an ecological perspective: How a teacher perceives affordance and fosters learner agency in a technology-mediated language classroom." ReCALL 30 (1):68-87.

Pittaway, Luke, Maxine Robertson, Kamal Munir, David Denyer, and Andy Neely. 2004. "Networking and innovation: a systematic review of the evidence." International journal of management reviews 5 (3 - 4):137-168.

Risager, K. (2007). Process and culture pedagogy: From a national to a transnational paradigm. Clevedon: Multilingual Matters.

Rosell-Aguilar, Fernando. 2017. "State of the App: A Taxonomy and Framework for Evaluating Language Learning Mobile Applications." CALICO journal 34 (2).

Shiri, Sonia. 2015. "Intercultural communicative competence development during and after language study abroad: Insights from Arabic." Foreign Language Annals 48 (4):541-569.

Sinicrope, Castle, John Norris, and Yukiko Watanabe. 2007. "Understanding and assessing intercultural competence: A summary of theory, research, and practice (technical report for the foreign language program evaluation project)." University of Hawai'I Second Langauge Studies Paper 26 (1).

$\mathrm{Wu}$, Jen-Her, Robert D Tennyson, and Tzyh-Lih Hsia. 2010. "A study of student satisfaction in a blended e-learning system environment." Computers \& Education 55 (1):155-164.

World Bank, (2017). China can provide leadership for global economy. http://www.worldbank.org/ en/news/opinion/2017/01/17/china-can-provide-leadership-for-global-economy, retrieved on the 6th May, 2017.

Yang, Chunsheng, and Ying Xie. 2013. "Learning Chinese idioms through iPads." Language Learning \& Technology 17 (2):12-23.

Yeung, Irene YM, and Rosalie L Tung. 1996. "Achieving business success in Confucian societies: The importance of guanxi (connections)." Organizational Dynamics 25 (2):54-65. 
APPENDIX A

AN OVERALl OF SPECIFICATIONS OF THE PROGRAMME

\begin{tabular}{|c|c|c|}
\hline Item & Content & Detail \\
\hline Duration & Year-long part-time & $\begin{array}{l}\text { Total contact hours: } \mathbf{2 7 0} \text { hours (excluding the } \\
\text { two weeks in China) } \\
\text { - Face-to-face teaching weekly: } 2 \mathrm{hrs} / \text { week * } \\
40 \text { weeks }=80 \text { hours } \\
\text { - China business Briefings with receptions *3 } \\
\text { - Full day Saturday sessions * } 10 \\
\text { - Cultural events * } 3 \\
\text { - Organised HSK/BCT examinations } * 3 \\
\text { - Catch-up classes in case you miss a class *6 } \\
\text { - Learning support through online platforms } \\
\text { and mobile apps }\end{array}$ \\
\hline Learners & $\begin{array}{l}\text { Business executives and } \\
\text { professionals }\end{array}$ & $\begin{array}{l}6 \text { language levels (from complete beginners } \\
\text { to proficiency) } \\
\text { Class Capacity: Maximum } 12 \text { per class }\end{array}$ \\
\hline \multirow[b]{3}{*}{$\begin{array}{l}\text { Skills/Learning } \\
\text { outcomes }\end{array}$} & $\begin{array}{l}\text { Being able to be engaged in } \\
\text { informal conversations before } \\
\text { getting down to business }\end{array}$ & $\begin{array}{l}\text { Emphasis on listening and speaking skills on } \\
\text { business context rather than reading and } \\
\text { writing Chinese characters }\end{array}$ \\
\hline & $\begin{array}{l}\text { Having sufficient knowledge } \\
\text { about Chinese culture and } \\
\text { approaches to business }\end{array}$ & $\begin{array}{l}\text { Provide students with deeper understanding } \\
\text { of Chinese core values, communication styles } \\
\text { and develop their intercultural competence }\end{array}$ \\
\hline & $\begin{array}{l}\text { Meeting like-minded people } \\
\text { and expanding their global } \\
\text { business worlds }\end{array}$ & $\begin{array}{l}\text { Lectures and events are designed to optimise } \\
\text { students' learning experience and provide } \\
\text { them with networking opportunities: } \\
\text { - China Business Briefing series held at LSE; } \\
\text { - VIP receptions after each China Business } \\
\text { Briefing to have an in-depth conversation } \\
\text { with speakers, peers and other native Chinese } \\
\text { attendees; } \\
\text { - Six China Business Briefings throughout the } \\
\text { year and students on CLCB programmes are } \\
\text { invited to all and entitled to three VIP } \\
\text { receptions; } \\
\text { - Intercultural communication training in } \\
\text { action }\end{array}$ \\
\hline \multirow[b]{2}{*}{ Assessment } & Formative & Moodle quiz with e-feedback every month. \\
\hline & HSK examinations & $\begin{array}{l}\text { HSK/BCT qualification preparation classes } \\
\text { on the first Saturday of each month. } \\
\text { Each class lasts } 3 \text { hours } * 10 \text { consecutive } \\
\text { months }=\mathbf{3 0} \text { hours }\end{array}$ \\
\hline
\end{tabular}




\begin{tabular}{|c|c|c|}
\hline \multirow{3}{*}{ Technology } & Moodle & $\begin{array}{l}\text { Offering flexible and accessible course site } \\
\text { for each level: } \\
\text { Each course site contains } 4 \text { key components: } \\
\text { 1. Course content } \\
\text { Teaching video with weekly highlight } \\
\text { from classroom learning and additional } \\
\text { learning materials } \\
\text { 2. Individualised materials } \\
\text { Texts, reading and vocabulary list that are } \\
\text { relevant to their particular business } \\
\text { industry or interest } \\
\text { 3. Online quizzes and e-feedback } \\
\text { 4. Discussion forum }\end{array}$ \\
\hline & Apps & $\begin{array}{l}\text { - Chinese apps: Alipay and Wechat } \\
\text { - Three free apps: Pleco, HSK app and } \\
\text { Wechat } \\
\text { - The paid app: Yiya Hanyu } \\
\text { Indispensable for business communication in } \\
\text { China } \\
\text { Specific skills: vocabulary, examination } \\
\text { preparation, speaking and listening, } \\
\text { pronunciation and business communication in } \\
\text { China }\end{array}$ \\
\hline & Skype & $\begin{array}{l}\text { Online drop-in sessions are offered weekly, } \\
\mathbf{3 0} \text { mins length each } \\
\text { Aim at conversational practice } \\
\text { Students can also use it to ask grammatical } \\
\text { questions or consolidate the course content }\end{array}$ \\
\hline \multirow[b]{2}{*}{ Study trip } & Pre-departure training & $\begin{array}{l}\text { Introduction to Tsinghua and Beijing; all } \\
\text { logistic issues of living and traveling in China }\end{array}$ \\
\hline & $\begin{array}{l}\text { Intensive Chinese Business } \\
\text { language programme in } \\
\text { Tsinghua University, } \\
\text { Beijing, China } \\
\end{array}$ & $\begin{array}{l}\text { - } 3 \text { hours of language learning every day } \\
\text { - } \text { field trips } \\
\text { - } \text { cultural talks } \\
\text { - } \text { networking events } \\
\end{array}$ \\
\hline $\begin{array}{l}\text { On-going } \\
\text { support }\end{array}$ & $\begin{array}{l}\text { - Free consultation with the } \\
\text { programme director before } \\
\text { the course starts } \\
\text { - Monthly newsletters } \\
\text { - Course evaluation by } \\
\text { learners every two months, } \\
\text { to adjust the course }\end{array}$ & $\begin{array}{l}\text { Detailed needs-analysis with individual } \\
\text { student } \\
\text { Monthly updates about students, staff, } \\
\text { China-related events on campus and around } \\
\text { London } \\
\text { Different communication and feedback } \\
\text { channels for learners }\end{array}$ \\
\hline
\end{tabular}

